\title{
AVALIAÇÃO DA MATURIDADE DE UM ESCRITÓRIO DE GERENCIAMENTO DE PROJETOS DA FIOCRUZ: UM CASO DE SUCESSO
}

\author{
Jefferson de Alencar \\ Ponciano Ramos \\ jeffersonponciano@bol.com.br \\ Universidade Federal Fluminense - \\ UFF, Niteroi, RJ. Brasil.
}

\section{Lisâneo Macedo Moreira Melo \\ lisaneo.melo@fiocruz.br Fundação Oswaldo Cruz - Fiocruz, Rio de Janeiro, RJ, Brasil.}

\section{Edinelson Benedito Alves de} Azevedo

edibenaz@ensp.fiocruz.br

Fundação Oswaldo Cruz - Fiocruz, Rio de Janeiro, RJ, Brasil.

\section{RESUMO}

Destaques: Muitas empresas desenvolvem suas atividades orientadas por projetos que as ajudam a alcançar os seus objetivos. Escritórios de projetos estão sendo utilizados pelas organizações para ajudá-los a planejar, desenvolver, monitorar e corrigir eventuais desvios nos projetos que fazem parte do seu portfólio. O gerenciamento prestado pelos escritórios pode contemplar estas etapas, suprimir alguma ou até fornecer um serviço específico conforme a necessidade da organização. A mensuração da maturidade de um escritório de projetos pode ser feita por algumas metodologias, fornecendo subsídios para avaliar a escolha do melhor caminho. Objetivo: Avaliar a maturidade de um escritório de gerenciamento de projetos de uma organização. Desenho/Metodologia/Abordagem: Foi utilizado o modelo do PMO Maturity Cube através da aplicação de um questionário específico que foi respondido pela gestora do escritório em estudo. Também foi indagado através de um questionário semiestruturado e diversas interações durante o período compreendido entre julho e agosto de 2020. Consultamos diversos documentos produzidos pelo escritório e por alguns stakeholders. As respostas e os documentos subsidiados forneceram dados para a realização de análises quantitativas e qualitativas. Resultados: 0 presente trabalho permitiu verificar o alinhamento entre as atividades desenvolvidas pelo Escritório de Projetos da Presidência (EPP) da Fundação Oswaldo Cruz (Fiocruz) com o objetivo para o qual foi criado. Limitações da investigação: A não utilização de outros métodos de avaliação da maturidade de um escritório de gerenciamento de projetos e a não extrapolação dos resultados para outros escritórios da Fiocruz. Implicações práticas: Este estudo forneceu uma oportunidade de autoavaliação e reflexão por parte da gestão do escritório sobre a sua atuação, proporcionando oportunidades de melhoria. Originalidade/valor: Análise ponto a ponto de todas as vinte e sete perguntas fornecidas pelo modelo.

Palavras-chave: Gestão de projeto; escritório de gerenciamento de projetos (EGP); project management office (PMO); mensuração da maturidade; Fiocruz. 


\section{INTRODUÇÃO}

A mais destacada instituição de ciência e tecnologia em saúde da América Latina, a Fiocruz, vinculada ao Ministério da Saúde, tem como missão a promoção da saúde e o desenvolvimento social, gera e difunde conhecimento científico e tecnológico, sendo ainda uma agente de cidadania. Destaca-se também pela busca incessante da excelência em gestão, e uma poderosa ferramenta utilizada na busca desta excelência é o EGP, setor em estudo neste trabalho, que se propõe a avaliar através de pesquisa bibliográfica e de campo o nível de maturidade do escritório de gerenciamento de projetos da presidência da Fiocruz e identificar ações para que esta gerência alcance o nível desejado, além de contribuir para a literatura com o engrandecimento do acervo de estudos relacionados ao tema.

Primeiramente são descritas as definições de elementos que compõem o contexto de um escritório de projetos, logo após é identificado o EPP, em seguida é caracterizado qual modelo de EGP é mais adequado a essa gerência e, finalmente é aferido o seu nível de maturidade.

\section{MÉTODOS}

Na literatura científica encontramos poucos modelos de mensuração de maturidade de EGP e tampouco modelos padrões aceitos pela comunidade científica, sendo que a maioria dos modelos são desenvolvidos por indústrias que encomendam suas necessidades à empresas de consultoria com experiência na área (Khalema et al., 2015).

Normalmente menciona-se o estudo de Pinto et al. (2010) por sua abordagem estratégica e pelo desenvolvimento do conceito de funções desenvolvidas por um EGP (Monteiro et al., 2016, apud Silva, 2018), mas poucos trabalhos realizaram a mensuração da maturidade através do modelo por eles proposto (Khalema et. al., 2015, apud Silva, 2018).

Neste contexto este artigo utilizará o modelo de avaliação de maturidade desenvolvido por Pinto et al., (2010) denominado PMO Maturity Cube, o qual avalia a maturidade através da aplicação de um questionário composto por 27 perguntas de múltipla escolha divididas em 10 perguntas referentes à abordagem estratégica, 9 referentes à abordagem tática e 8 referentes à abordagem operacional. A decisão pela aplicação do questionário departamental se deu pela análise da função do EPP e pelo depoimento da sua gestora:

"O EPP é um PMO que cuida de todas as unidades ligadas à Presidência, mas não da FIOCRUZ como um todo" (Carneiro, 2020).

Em paralelo e como forma de apoio à análise do questionário modelo, foi aplicado um outro específico desenvolvido pelos autores deste artigo, o qual procurou entender um pouco sobre a criação do EPP da Fiocruz, bem como a experiência em gestão de projetos dos profissionais que nele atuam.

Procurou-se evidências para amparar as respostas ao questionário do modelo, e tais evidências foram encontradas em diversos documentos fornecidos pela gestora do EPP e no site da Fiocruz, tais como "relatórios de auditorias interna e externa", "planos de auditoria", "rota estratégica do EPP", "relatório de atividades do EPP", "relatório de análise crítica (RAC)", "portarias da presidência da Fiocruz", "plano de desenvolvimento de pessoas", "organograma" e "relatório de avaliação de desempenho".

Os questionários foram aplicados diretamente à gestora representante do EPP, porém, a opinião dos demais integrantes do escritório também se fizeram presente, pois o "relatório de avaliação de desempenho" utilizado na pesquisa foi desenvolvido por toda a equipe.

Após o recebimento de todas as respostas do questionário modelo, o qual é o principal deste estudo, foi realizada uma análise qualitativa onde as respostas foram analisadas e confrontadas com os diversos documentos de pesquisa disponibilizados pela Fiocruz, sendo que evidenciou-se o pleno alinhamento da percepção da respondente com o que está documentado ou encontrou-se oportunidades de meIhoria, na maioria das vezes, também amparadas por ações futuras descritas nos documentos de apoio.

O passo seguinte foi uma análise quantitativa, onde comparou-se a pontuação alcançada entre as respostas para os níveis atual e desejado e entre os níveis atual e máximo para classificar o nível de maturidade do EPP nas abordagens estratégica, tática e operacional.

As conclusões foram amparadas tanto pela análise qualitativa como pela quantitativa, as quais se complementam perfeitamente neste trabalho.

De forma a proporcionar um nivelamento de informações ao leitor, apresentamos abaixo alguns conceitos de termos relacionados ao gerenciamento de projetos.

\section{Projeto}

Projeto "é um esforço temporário empreendido para criar um produto, serviço ou resultado exclusivo" (Project Management Institute - PMI, 2017, p. 4).

"Trata-se de um empreendimento com objetivo bem definido, que consome recursos e opera sob pressão de prazos, custo e qualidade. Além disso, projetos são considerados atividades exclusivas em uma empresa" (Kerzner, 2006, p. 15). 
Nota-se que a exclusividade é um adjetivo comum às duas definições e percebe-se que a palavra projeto neste contexto nos remete a algo muito maior do que um projeto arquitetônico; projeto na disciplina gerenciamento de projetos remete ao meio utilizado para a concretização de uma necessidade de uma organização, seja ela em qualquer área de conhecimento.

\section{Gestão de projetos}

“Gerenciamento de projetos é a aplicação de conhecimentos, habilidades, ferramentas e técnicas às atividades do projeto a fim de cumprir os seus requisitos" (PMI, 2017, p.10).

"Gerenciamento de Projetos é um ramo do conhecimento que versa sobre o planejamento, monitoramento e controle de empreendimentos exclusivos, que caracterizam os projetos" (Dinsmore, 2009, p.05).

Pode-se inferir que gestão de projetos é a arte de estruturar a forma de como o projeto é planejado, executado, monitorado e controlado para cumprir os seus objetivos.

\section{Escritório de projetos}

De forma geral, “o PMO é uma área que centraliza determinadas atividades, também chamadas de funções, relacionadas à prática de gerenciamento de projetos, com o objetivo de fazer com que a organização alcance melhores resultados por meio de projetos" (Pinto et al., 2010, p. 03).

Um EGP “é uma estrutura organizacional que padroniza os processos de governança relacionados a projetos $\mathrm{e}$ facilita o compartilhamento de recursos, metodologias, ferramentas e técnicas. As responsabilidades de um EGP podem variar desde o fornecimento de funções de apoio ao gerenciamento de projetos até o gerenciamento direto de um ou mais projetos" (PMI, 2017, p.48).

De acordo com as definições, EGP é uma entidade voltada a apoiar a implantação, execução, monitoramento e encerramento de projetos dentro de uma organização, ou, em alguns casos, é o responsável pela condução direta de um ou vários projetos. Sua configuração depende do propósito para o qual foi idealizado e quais os objetivos propostos.

Segundo Pinto et al. (2010), não é incomum encontrarmos um PMO corporativo prestando serviços nas abordagens estratégica (quando este apoia diretamente a alta administração), tática (quando padroniza uma metodologia para a organização) e operacional (quando assume para si a gestão direta do projeto). O fato é que na vida real fre- quentemente temos que combinar as três abordagens tanto para escritórios corporativos como para os departamentais e para os programas-projeto.

\section{Maturidade em gestão de escritório de gerenciamento de projetos}

"O grau de maturidade de um $P M O$ é resultado do quanto ele é capaz de gerar valor para seus clientes e para a organização como um todo. E a evolução deste $P M O$ se dará de acordo com o amadurecimento da organização, o que fará com que seus clientes passem a ter necessidades diferentes e, em geral, cada vez mais sofisticadas". (Pinto et al., 2010)

Ainda há a necessidade de evoluirmos na questão da maturidade de escritório de gerenciamento de projetos, pois poucos modelos são reconhecidos e disponíveis. Entre eles citamos o PMO Maturity Model e o PMO Maturity Cube, sendo este último o modelo a ser estudado neste trabalho.

Embora não muito explorado em estudos de caso, nota-se uma preferência pelo modelo PMO Maturity Cube no trabalho de alguns pesquisadores, talvez porque sua essência nasceu de um mapeamento da função exercida por PMOs em várias partes do mundo. As 27 funções preconizadas neste modelo tiveram como base uma pesquisa realizada por Aubry et al. (2008), onde mapearam as atividades realizadas por aproximadamente 500 PMOs.

Para os autores do modelo, quanto melhor o PMO presta seus serviços relacionados às funções necessárias, maior valor agregado o PMO traz à organização.

Por meio de um questionário específico para cada amplitude de $P M O$, o modelo identifica quais serviços são oferecidos sob cada diferente abordagem, e com que nível de sofisticação eles são executados.

Cada um dos três questionários (corporativo, departamental, programa-projeto) é dividido em três partes: avaliação dos serviços estratégicos, táticos e operacionais. No preenchimento as organizações informam qual o estágio de maturidade atual em cada serviço previsto para aquela determinada amplitude, bem como qual o estágio de maturidade desejado para o PMO sob análise, ou seja, trata-se de uma autoavaliação.

Cada estágio corresponde a uma pontuação específica e, ao fim do preenchimento, são obtidas as pontuações totais correspondentes à situação atual da organização e à situação desejada, divididas nas abordagens estratégica, tática e operacional. Com base nessas pontuações são calculados os níveis de maturidade atual e desejado. 
O nível de maturidade atual em cada uma das abordagens é dado pela comparação entre a pontuação relativa à situação atual da organização com o total de pontos possíveis de serem obtidos no modelo. Já o nível de maturidade desejada é dado pela comparação entre a pontuação relativa à situação desejada da organização com o total de pontos possíveis de serem obtidos no modelo.

A maturidade atual e a desejada são representadas por meio de percentuais. $O$ nível de maturidade atual representa o quanto o $P M O$ está aderente a todos os serviços possíveis a um $P M O$ em seu mais alto estágio de maturidade. Já o nível de maturidade desejada representa onde o $P M O$ gostaria de chegar, situação na qual estaria plenamente aderente aos seus objetivos e missão, considerando apenas os serviços que de fato Ihe interessam nos estágios de maturidade esperados.

Conforme Pinto et al. (2010), o modelo PMO Maturity Cube classifica a maturidade em três níveis. $O$ nível básico corresponde ao percentual de $0 \%$ a $33 \%$ e é atingido no momento inicial do $P M O$. O nível intermediário corresponde ao percentual de $34 \%$ a $60 \%$ e corresponde aos escritórios que possuem atribuições específicas a serem desempenhadas. 0 nível avançado corresponde ao percentual de $61 \%$ a $100 \%$ e é alcançado pelos escritórios que detém conhecimento para executar adequadamente suas atividades.

A Figura 1 abaixo ilustra os níveis de maturidade, a amplitude e as abordagens do modelo.

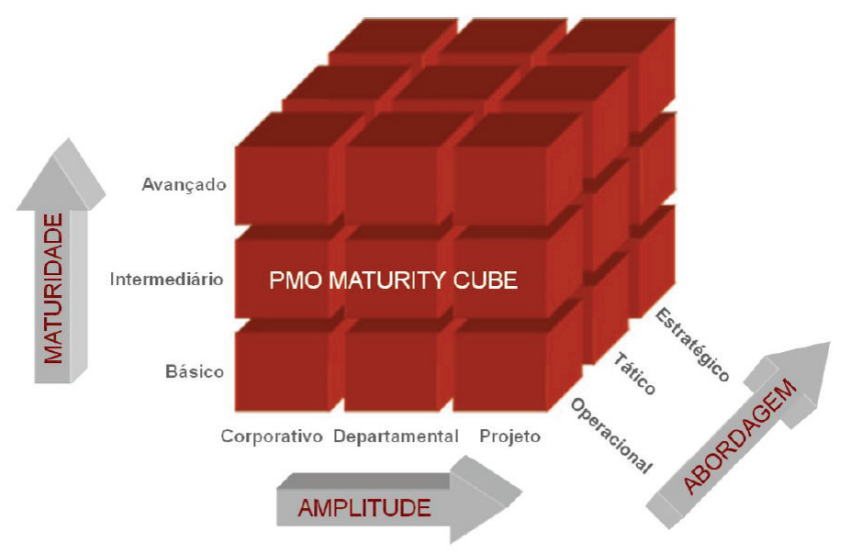

Figura 1. As três dimensões do PMO Maturity Cube Fonte: Pinto, Cota e Levin (2010)

\section{PMO Fiocruz}

O EPP foi criado em agosto de 2018 com o objetivo de contribuir para o desenvolvimento científico e tecnológico da Fiocruz por meio da busca da excelência no gerenciamento de projetos da Presidência.
Como estratégia desse processo de aperfeiçoamento, foram empregadas ferramentas de gestão dos projetos para racionalizar o uso de recursos financeiros e humanos, padronizar os modos de avaliação de desempenho, com especial atenção à integração de iniciativas semelhantes e à articulação de iniciativas complementares.

A criação do escritório visa ainda garantir no desenvolvimento dos projetos os melhores princípios de governança que devem nortear todos os entes da administração pública.

O EPP presta serviço de gerenciamento de projetos no âmbito da Presidência da fundação e suas estruturas.

O EPP ainda possui três "gerentes" que dividem entre si a responsabilidade administrativa, cada qual com uma carteira de projetos. Eles são funcionários terceirizados e auxiliam administrativamente os "coordenadores", nome dado aos gerentes técnicos de cada projeto, os quais são servidores estatutários, em todas as etapas do ciclo de vida do projeto.

\section{RESULTADOS}

Nesta seção serão discutidas as respostas a todas as perguntas do modelo PMO Maturity Cube, bem como sua correlação com documentação produzida pelo EPP e/ou órgãos externos que corroboram com as respostas ou definem oportunidades de melhoria conforme desejado em cada questão.

No quesito "prover aconselhamento à Alta Gerência do Departamento", em alinhamento com o objetivo de garantir os melhores princípios de governança* que devem nortear todos os entes da administração pública e com a atribuição dada por Mansur (2009) Suporte e Apoio para a Alta administração, o EPP demonstra o nível atual igual ao desejado, o que corresponde ao nível máximo do modelo e que também vem ao encontro da matriz de análise e julgamento, parte integrante do "relatório de avaliação de desempenho 2019" do EPP, onde os integrantes da equipe avaliam que o EPP traz subsídios à tomada de decisão da alta direção atribuindo nota máxima para este indicador (Relatório Final de Pesquisa, 2020, p. 169) .

*Na dimensão Governança, os critérios foram fornecer 'subsídios à tomada de decisão da alta direção'... (Relatório Final de Pesquisa, 2020, p. 133).

Apesar de não constar como objetivo na criação do EPP, é um desejo identificar interdependências existentes entre os projetos e/ou programas componentes do portfólio do departamento, porém, sem acompanhar as mudanças nestas interdependências, o que corresponde ao nível 1 do modelo, e isto ficou registrado no item lições aprendidas do "relatório de avaliação de desempenho", onde diz que "A 
criação e divulgação de um portfólio de projetos gerenciados pelo EPP favorece tanto a disseminação dos produtos da pesquisa para o público em geral, como também favorece o fortalecimento do EPP como escritório de gerenciamento de projetos no campo da saúde pública" (Relatório Final de Pesquisa, 2020, p. 142).

No quesito "Desenvolver e manter um quadro estratégico de projetos e/ou programas do departamento", o EPP encontra-se no nível 1 do modelo, que é o nível desejado, porém, não o mais alto, pois disponibiliza informações referentes aos projetos e programas componentes do portfólio do departamento em um painel de controle executivo, mas este não é frequentemente utilizado pela alta gerência do departamento como apoio à tomada de decisão, conforme demonstra o seguinte depoimento da gestora do EPP: "Nós disponibilizamos as informações e a diretoria de planejamento estratégico de toda a Fiocruz que faz análises e cuida do portfólio" (Carneiro, 2020).

Como não poderia deixar de ser, em estrito alinhamento com o objetivo para que foi criado, ou seja, ser uma instância estratégica para a Presidência da Fiocruz no sentido de atuar no gerenciamento de projetos e acompanhá-los por meio de atividades de planejamento, monitoramento, controle e avaliação com os objetivos de unificar a gestão de projetos e estruturar processos de qualificação de projetos, desempenhando também um papel normativo de forma articulada com o Gabinete da Presidência e a Vice-Presidência de Gestão e Desenvolvimento Institucional - VPGDI, o EPP encontra-se no nível máximo do modelo no quesito "promover o gerenciamento de projetos no departamento", pois define e executa um plano estruturado de promoção do gerenciamento de projetos em todos os níveis do departamento, revisa e melhora políticas e diretrizes para o gerenciamento de projetos no departamento.

No que tange aos processos finalísticos, em consonância com o que preconiza o Project Management Body of Knowledge (PMBOK), o EPP faz a iniciação, o planejamento, a execução e o encerramento do projeto, sempre com monitoramento e controle de todas as etapas (Relatório Final de Pesquisa, 2020, p. 48).

Os processos internos que sustentam todas as etapas descritas, alguns realizados pela Fundação para o Desenvolvimento Científico e Tecnológico em Saúde (Fiotec) ou por alguma equipe de apoio à gestão, são a gestão de suprimentos, execução orçamentária e financeira, eventos e reuniões, bolsas, arquivos, passagens e diárias, prestação de contas e protocolo e expedição (Relatório Final de Pesquisa, 2020, p. 78, 107, 108, 114, 120 e 157).

O nível máximo foi atingido no quesito monitorar e controlar o seu próprio desempenho, pois solicita formalmen- te aos seus clientes um retorno sobre o seu desempenho e possui indicadores de desempenho para os processos sob a sua responsabilidade, demonstrando continuamente o seu desempenho para os seus clientes. Além disso, compartilha metas com seus clientes e estrutura-se para melhoria contínua e aumento de sua maturidade, avaliando a necessidade de eliminação, manutenção ou criação de novos serviços.

Esta dinâmica é evidenciada no "relatório de avaliação de desempenho", o qual diz que neste relatório serão apresentados os resultados e produtos sistematizados da pesquisa avaliativa "Avaliação do Desempenho e Gestão do Conhecimento no Escritório de Projetos da Presidência da Fundação Oswaldo Cruz", realizada no período de julho de 2017 a dezembro de 2019 (Relatório Final de Pesquisa, 2020, p. 9).

Apesar do EPP ter alcançado o nível máximo nesta função segundo o modelo estudado, nota-se uma oportunidade de melhoria citada no próprio "relatório de avaliação de desempenho", que seria analisar a satisfação dos usuários dos serviços do EPP (Relatório Final de Pesquisa, 2020, p. 132).

Na função participar do processo de planejamento estratégico do departamento, o EPP foi pontuado no nível 2 , pois participa informalmente e regularmente do processo de planejamento estratégico do departamento, e a meta é participar formalmente deste processo. Apesar de o "relatório de avaliação de desempenho" demonstrar que a dimensão planejamento é desdobrada em planejamento de atividades de médio e longo prazo, este planejamento é limitado ao próprio EPP, não se estendendo ao departamento, conforme depoimento da sua gestora: "Quadrienalmente é realizado um congresso interno com representantes de todas as unidades da Fiocruz, onde é gerado o plano estratégico quadrienal que é desdobrado para todas as unidades até chegar ao nível do departamento, e somente os eleitos têm direito a voto na definição do referido plano" (Carneiro, 2020).

Como nenhum representante do EPP foi eleito no último congresso, a sua participação na definição das metas foi informal, sendo um objetivo participar formalmente no próximo ciclo.

Alinhado com a atribuição do EPP de ampliar e consolidar o processo de monitoramento e avaliação de projetos e à garantia da eficácia e efetividade dos projetos, no quesito gerenciar um ou mais portfólios departamentais, o nível atual é 3, pois o EPP possui uma lista dos projetos ativos e priorizados do departamento e estabelece processos formais atuando como facilitador na definição (identificação, categorização, avaliação, seleção), desenvolvimento (priorização, balanceamento e autorização) e execução (monitoramento, revisão e gestão de mudanças) do portfólio, porém, não possui um sistema integrado para automatizar 
os processos de gestão deste portfólio, e a automatização deste processo é uma meta do EPP.

Uma evidência de que o EPP encontra-se no estágio 3 deste quesito pode ser encontrada no "relatório de avaliação de desempenho", o qual diz que a gestão estratégica de projetos, componente que envolve a coordenação do EPP e a equipe de monitoramento e avaliação busca a adequação dos projetos às diretrizes e princípios supra descritos, além de monitorar e avaliar sua execução (Relatório Final de Pesquisa, 2020, p. 49).

Diante da resposta à função identificar, selecionar e priorizar novos projetos do departamento, torna-se claro que esta não é uma atribuição do EPP, pois 0 é o nível atual e o desejado, ou seja, o EPP não executa essa função. Esta resposta também está em conformidade com o objetivo e as atribuições definidas no ato de criação do EPP, pois nenhuma delas cita novos projetos (Portaria 1070/2018-PR). Todo o portfólio disponibilizado para o gerenciamento por parte do EPP é definido pela Fiocruz.

Com relação à função gerenciar os benefícios de projetos ou programas do departamento o EPP se autoavalia no nível 2, que é o nível máximo do modelo. Ele acompanha a evolução da realização dos benefícios esperados para o departamento durante e após seu fim, avaliando os resultados de negócio e comparando-os com os objetivos estratégicos originais do departamento vinculados ao planejamento estratégico. Anualmente é emitido um relatório de atividades do EPP e, evidenciando a autodefinição deste item, temos o registro de que o escritório de projetos estabeleceu medidas para a prevenção de possíveis desvios nos resultados esperados do gerenciamento de projetos de cooperação técnica da presidência ao criar e aprimorar estruturas de governança, riscos e controles (Relatório de Atividades do EPP, 2018, p. 25).

Neste mesmo relatório vemos que um dos resultados da gestão estratégica de projetos do EPP é a correção de possíveis desvios a partir da análise dos resultados apontados pelos indicadores de desempenho (Relatório de Atividades do EPP, 2018, p. 9).

A última função estratégica disponibilizada pelo modelo estudado é mapear o relacionamento e o ambiente de projetos dentro e fora do departamento, a qual o EPP se autodefiniu no nível 2, nível máximo para esta função, na qual o EPP identifica os stakeholders do portfólio do departamento, analisa suas expectativas, cria uma estratégia de relacionamento e atua proativamente para implementá-la.

No objetivo definido formalmente para o EPP encontra-se uma vertente de relacionamento com os stakeholders, pois uma de suas funções é desempenhar também um papel normativo de forma articulada com o Gabinete da Presidên- cia e a Vice-Presidência de Gestão e Desenvolvimento Institucional (Portaria 1070/2018-PR).

No "relatório de avaliação de desempenho" também encontramos a menção quanto a analisar a mobilização da rede sociotécnica e a trajetória da execução e resultados das pesquisas desenvolvidas quanto ao envolvimento e participação dos interessados, bem como a busca pela compreensão das relações em rede que se estabelecem internamente do EPP com a Fiocruz e seus setores implicados na realização dos projetos (Relatório Final de Pesquisa, 2020, p. 16).

Outra evidência de atendimento pleno a esta função é a menção no "relatório de auditoria", que diz que nos documentos DOC-EPP-04 mapa de Stakeholders rev. 00 e DOC-EPP-02 expectativa das partes interessadas rev. 00, estão determinadas as partes interessadas e as suas expectativas que são controladas e monitoradas através dos indicadores (Relatório de Auditoria ISO 9001:2015, 2019, p. 9).

A seguir são apresentadas as tabulações com as notas atribuídas pelo próprio EPP ao seu nível atual e ao nível desejado, bem como é mostrado qual a nota máxima possível de ser alcançada para cada questão estratégica.

Focando agora na abrangência tática, temos o item desenvolver e implementar a metodologia padrão de gerenciamento de projetos do departamento. Neste quesito, o EPP também se considera no nível máximo do modelo, nível 4, pois ele desenvolve e aprimora a metodologia padrão para o departamento e esta é utilizada de forma ampla e correta. Na matriz de análise e julgamento produzida pelos integrantes do EPP no "relatório de avaliação de desempenho", considerou-se que a metodologia adotada pelo EPP é definida (Relatório Final de Pesquisa, 2020, p. 171), ou seja, ela é madura o suficiente para ser utilizada pelo departamento.

Correlacionando-se com as atribuições formais do EPP, tem-se estruturar modelo de gestão para escritório de projetos propondo políticas efetivas de controle estratégico e operacional em gerenciamento de projetos e propor aperfeiçoamento dos mecanismos de gestão de projetos existentes (Portaria 1070/2018-PR).

Um ponto forte identificado pelo modelo é a função desenvolver competências em gerenciamento de projetos, no qual o EPP estabelece uma carreira específica em gerenciamento de projetos para o departamento sustentada por um plano de desenvolvimento corporativo de competências em gerenciamento de projetos envolvendo treinamentos, certificações e/ou pós-graduações, o que corresponde ao nível 4, nível máximo do modelo.

Mais uma vez tem-se o alinhamento com as atribuições do EPP, neste caso na atribuição de aprimorar os processos 
de gestão do conhecimento e gestão da pesquisa aplicados ao gerenciamento de projetos (Portaria 1070/2018-PR). O "relatório de avaliação de desempenho" mostra que é fornecido treinamento inicial em EGP para todos os novos profissionais analistas de projetos (Relatório Final de Pesquisa, 2020, p. 177), e o "relatório de auditoria" ISO 9001:2015 nos mostra que as necessidades de contratação de pessoas, as necessidades quanto à educação dos colaboradores e as necessidades de treinamentos para as funções executadas estão descritas no DOC-EPP-05 competências organizacionais do EPP rev. 00 (Relatório de Auditoria ISO 9001:2015, 2019, p. 11).

Uma oportunidade de melhoria foi encontrada na função implementar e administrar sistemas de informação de gerenciamento de projetos, pois, segundo a gestora do EPP, ele oferece um sistema de informação de gerenciamento de projetos para o departamento com foco em monitoramento e controle, o qual é utilizado por gerentes de projetos/programas e stakeholders na maioria dos projetos do departamento, porém, este sistema não utiliza uma base de dados única e integrada com todos os projetos, o que corresponde ao nível 1 do modelo, e o nível desejado é 3, nível máximo para esta função que, além da descrição dada acima, ainda oferece um sistema de informação de gerenciamento de projetos integrado para o departamento e que é efetivamente utilizado por gerentes de projetos/programas e stakeholders em todos os projetos do departamento.

A ação de longo prazo (2025-2028), integração dos processos de trabalho e tecnologias, pode ser um caminho para que o EPP alcance o nível desejado (Rota Estratégica do EPP da Fiocruz, 2018, p. 2).

$\mathrm{Na}$ função gerenciar interfaces com clientes, verificamos que a fundação, no caso representada pelo EPP, faz uma pesquisa de satisfação aos clientes pós-entrega de projeto através da FRM-EPP-40, pesquisa de satisfação de clientes (pós entrega) rev. 00 e também que a sistemática de pesquisa de satisfação está determinada no DOC-EPP-07, pesquisa de satisfação rev. 00 (Relatório de Auditoria ISO 9001:2015, 2019, p. 13). Esta constatação evidencia o nível máximo, no caso, o nível 3 autoatribuído pelo EPP nesta função, que é o de gerenciar o relacionamento com clientes dos projetos do departamento administrando expectativas, avaliando a satisfação e garantindo o cumprimento dos acordos estabelecidos, tendo autoridade para influenciar diretamente a gestão dos projetos envolvidos.

Apesar de não constar formalmente como objetivo e atribuição do EPP, na função de prover um conjunto de ferramentas para o gerenciamento de projetos, ele novamente se define no nível máximo do modelo, nível 3, onde provê ferramentas aderentes às metodologias e processos existentes padronizadas e integradas para o departamento, as quais são utilizadas plenamente.

As ações de curto prazo (2018-2020) corroboram com esta visão, tais como a utilização de tecnologia de nuvem para gestão de informações, definição da lista de distribuição, controle de acesso e cópias controladas dos documentos do EPP, implementação da política de gestão documental

Tabela 1. Resultados da Abordagem Estratégica

\begin{tabular}{|c|c|c|c|}
\hline Questões de Abordagem Estratégica & $\begin{array}{l}\text { Nível } \\
\text { Atual }\end{array}$ & $\begin{array}{l}\text { Nível } \\
\text { Desejado }\end{array}$ & $\begin{array}{l}\text { Nível } \\
\text { Máximo }\end{array}$ \\
\hline Como o PMO provê aconselhamento à Alta Gerência do Departamento? & 3 & 3 & 3 \\
\hline Como o PMO coordena e integra os projetos e/ou programas do portfólio do departamento? & 0 & 1 & 3 \\
\hline $\begin{array}{l}\text { Como o PMO desenvolve e mantém um quadro estratégico de projetos e/ou programas do } \\
\text { departamento (project/program scoreboard)? }\end{array}$ & 1 & 1 & 3 \\
\hline Como o PMO promove o gerenciamento de projetos no departamento? & 3 & 3 & 3 \\
\hline Como o PMO monitora e controla o seu próprio desempenho? & 4 & 4 & 4 \\
\hline Como o PMO participa do processo de planejamento estratégico do departamento? & 2 & 3 & 3 \\
\hline Como o PMO gerencia um ou mais portfólios departamentais? & 3 & 4 & 4 \\
\hline Como o PMO identifica, seleciona e prioriza novos projetos do departamento? & 0 & 0 & 3 \\
\hline Como o PMO gerencia os benefícios de projetos ou programas do departamento? & 2 & 2 & 2 \\
\hline $\begin{array}{l}\text { Como o PMO mapeia o relacionamento e o ambiente de projetos dentro e fora do departa- } \\
\text { mento? }\end{array}$ & 2 & 2 & 2 \\
\hline Pontuação Total & 20 & 23 & 30 \\
\hline
\end{tabular}

Fonte: Os próprios autores

Resultado atual em relação ao desejado: $86,96 \%$ = Avançado

Resultado atual em relação ao máximo: $66,67 \%$ = Avançado

Resultado desejado em relação ao máximo: 76,67\% = Avançado 
e confidencialidade, criação da lista-mestra dos formulários utilizados pelo EPP e de sua finalidade de uso, implementação da certificação ISO 9001:2015 INMETRO e implantação do programa gestão da qualidade (Rota Estratégica do EPP da Fiocruz, 2018, p. 1).

Também percebe-se um desejo de melhoria quando verificado entre as ações de longo prazo (2025-2028) a identificação dos diferentes sistemas de informações utilizados para cadastro, monitoramento e avaliação de projetos (Rota Estratégica do EPP da Fiocruz, 2018, p. 2).

No quesito atuar na alocação e movimentação de recursos entre os projetos do departamento, mais uma vez o nível 3, nível máximo do modelo foi indicado como o nível atual do EPP, pois, segundo a sua coordenação, ele possui uma visão do pool de recursos e autoridade para alocar e mover recursos entre projetos do departamento.

Em uma passagem do "relatório de avaliação de desempenho" é citado que, em relação aos projetos DAB Fito I e II, um fator de complexidade referiu-se ao processo de alocação de recursos, já que envolveu vários atores e instituições, o que demandou um maior apoio do EPP à gestão deste Termo de Execução Descentralizada (Relatório Final de Pesquisa, 2020, p. 120). Também havendo necessidade de contratação, a coordenação geral solicita à Fiotec, que é quem cuida de toda a parte dos recursos humanos relacionadas aos colaboradores (Relatório de Auditoria ISO 9001:2015, 2019, p. 11).

Na função implementar e gerenciar o banco de dados de lições aprendidas identificou-se uma oportunidade de meIhoria, uma vez que pretende-se passar do nível 1 , onde o EPP armazena as lições aprendidas dos projetos do departamento isoladamente sem uma integração das lições dos diversos projetos, não há estruturação de um banco de dados, para o nível 3, nível máximo deste quesito, onde além de consolidar, também implementa e dissemina uma ferramenta para recuperação de lições aprendidas para projetos do departamento.

Vê-se similaridade entre o armazenamento de lições aprendidas com a atribuição formal de aprimorar os processos de gestão do conhecimento e gestão da pesquisa aplicados ao gerenciamento de projetos (Portaria 1070/2018-PR).

Entre as ações de curto prazo do planejamento estratégico do EPP, vemos que a utilização de tecnologia de nuvem para gestão de informações pode estar alinhada com este desejo de estruturação de um banco de dados (Rota Estratégica do EPP da Fiocruz, 2018, p. 1). Também pode-se inferir um alinhamento com a estruturação de um banco de dados nas ações de médio prazo, implantação da gestão de documentos no EPP e desenvolvimento da área de gestão do conhecimento em projetos (Rota Estratégica do EPP da Fiocruz, 2018, p. 2).

Implementar e gerenciar o banco de dados de riscos é outra função onde verificou-se uma oportunidade de meIhoria, pois pretende-se passar do nível 2, consolida os riscos gerenciados nos projetos do departamento criando uma estrutura analítica de riscos e estrutura um banco de dados, para o nível 3, nível máximo, o qual, além de consolidar os riscos, ainda implementa e dissemina uma ferramenta para recuperação de informações sobre riscos.

Atestando o nível atual, temos que o controle dos riscos e oportunidades é realizado através da planilha de Riscos $\mathrm{G}$. Projetos_EPP, onde os riscos dos processos e os estratégicos que foram identificados na matriz de SWOT foram classificados através de critérios que determinam os riscos pequenos, médios e grandes (Relatório de Auditoria ISO 9001:2015, 2019, p. 11). Também podemos constatar no "relatório de avaliação de desempenho" que na planilha matriz de riscos do EPP há um plano de gerenciamento de riscos identificado (Relatório Final de Pesquisa, 2020, p. 160).

Para se alcançar o nível desejado podemos citar, a exemplo da função implementar e gerenciar o banco de dados de lições aprendidas, a ação de médio prazo utilização de tecnologia de nuvem para gestão de informações, a qual pode auxiliar na recuperação de informações (Rota Estratégica do EPP da Fiocruz, 2018, p. 2).

Curiosamente, na função de recrutar, selecionar, avaliar e determinar salários dos gerentes de projetos, apesar de ser uma fundação pública, segundo depoimento da coordenadora do EPP ele estabelece critérios para o recrutamento, seleção e avaliação de gerentes de projetos, além de estabelecer um plano de cargos e salários, o que novamente corresponde ao nível 3, nível máximo do modelo: "Os denominados gerentes de projetos são colaboradores do próprio EPP e exercem a função de apoio administrativo aos coordenadores técnicos de cada projeto da área de saúde, e a autonomia de recrutar, selecionar, avaliar e determinar salários é dada porque os gerentes de projetos são colaboradores terceirizados e não concursados" (Carneiro, 2020).

Na Tabela 2 são apresentadas as pontuações para a abordagem tática.

Quanto à abordagem operacional, temos outra oportunidade de melhoria, tendo em vista que no quesito prover serviços especializados para os gerentes de projetos, o EPP situa-se no nível 1 do modelo, proporcionando aos gerentes de projetos do departamento serviços mais básicos de apoio ao gerenciamento de projetos, como por exemplo, apoio à documentação, elaboração de cronogramas e facilitação de reuniões, e a intenção é, além desses serviços básicos, 
Tabela 2. Resultados da Abordagem Tática

\begin{tabular}{|c|c|c|c|}
\hline Questões de Abordagem Tática & $\begin{array}{l}\text { Nível } \\
\text { Atual }\end{array}$ & $\begin{array}{c}\text { Nível } \\
\text { Desejado }\end{array}$ & $\begin{array}{l}\text { Nível } \\
\text { Máximo }\end{array}$ \\
\hline $\begin{array}{l}\text { Como o PMO desenvolve e implementa a metodologia padrão de Gerenciamento de Proje- } \\
\text { tos do departamento? }\end{array}$ & 4 & 4 & 4 \\
\hline Como o PMO desenvolve competências em Gerenciamento de Projetos? & 4 & 4 & 4 \\
\hline $\begin{array}{l}\text { Como o PMO implementa e administra sistemas de informação de gerenciamento de } \\
\text { projetos? }\end{array}$ & 1 & 3 & 3 \\
\hline Como o PMO gerencia interfaces com clientes? & 3 & 3 & 3 \\
\hline Como o PMO provê um conjunto de ferramentas para o Gerenciamento de Projetos? & 3 & 3 & 3 \\
\hline $\begin{array}{l}\text { Como o PMO atua na alocação e movimentação de recursos entre os projetos do departa- } \\
\text { mento? }\end{array}$ & 3 & 3 & 3 \\
\hline Como o PMO implementa e gerencia o banco de dados de lições aprendidas? & 1 & 3 & 3 \\
\hline Como o PMO implementa e gerencia o banco de dados de riscos? & 2 & 3 & 3 \\
\hline $\begin{array}{l}\text { Como o PMO exerce as funções de recrutar, selecionar, avaliar e determinar salários dos } \\
\text { GPs? }\end{array}$ & 3 & 3 & 3 \\
\hline Pontuação Total & 24 & 29 & 29 \\
\hline
\end{tabular}

Fonte: Os próprios autores

Resultado atual em relação ao desejado: $82,76 \%$ = Avançado

Resultado atual em relação ao máximo: $82,76 \%$ = Avançado

Resultado desejado em relação ao máximo 100,00\% = Avançado

alcançar o nível 2, nível máximo do modelo para fornecer serviços mais avançados, tais como análise de riscos, elaboração e gestão de contratos e recuperação de projetos.

O "relatório de auditoria" ISO 9001:2015 evidencia uma parte dos serviços básicos descritos neste item quando relata que o operacional é responsável pelo gerenciamento administrativo dos projetos demandados pelos ministérios do governo federal no âmbito da presidência da Fiocruz, auxiliando os pesquisadores (clientes) da Fiocruz quanto à conta financeira destinada aos projetos (aprovada pelo ministério) e quanto ao cumprimento do cronograma de pesquisa relacionada aos assuntos demandados (Relatório de Auditoria ISO 9001:2015, 2019, p. 14).

A função administrativa também é relatada na atribuição formal realizar o acompanhamento das ações de cooperação no que ser refere aos aspectos administrativos junto com os responsáveis pelos projetos (Portaria 1070/2018-PR).

Quanto ao desejo de melhoria, a ação de recuperação de projetos pode ser correlacionada com a ação de médio prazo (2021-2024) implantação da gestão de documentos no EPP e da ação de longo prazo (2025-2028) desenvolvimento de programa de gestão do conhecimento para registro das melhores práticas, retenção por curso e apresentação de cases, onde a apresentação de cases pode trabalhar projetos já gerenciados pelo EPP (Rota Estratégica do EPP da Fiocruz, 2018, p. 2).
Uma evidência que sustenta a autodefinição no nível 2 do modelo na ação informar o status dos projetos para a alta gerência à medida que recebe a informação do status, analisa e disponibiliza relatório à alta gerência/sponsor do departamento, gerando alertas, é o indicativo disponibilizado no "relatório de avaliação de desempenho" de que as atividades do EPP têm servido de subsídios à tomada de decisão da alta direção (Relatório Final de Pesquisa, 2020, p. 169).

Não há interesse e nem é um objetivo avançar ao nível 3, nível máximo do modelo, o qual, além de informar o status conforme acima relatado, o EPP ainda teria que interagir com as partes interessadas em busca da solução dos problemas.

Monitorar e controlar o desempenho de projetos e programas do departamento é uma atribuição avaliada no nível máximo, nível 3 do modelo, tendo em vista que o EPP monitora e controla o desempenho de projetos e programas do departamento sob o ponto de vista de prazo, custo, qualidade e satisfação do cliente, provendo relatórios de acompanhamento e tomando proativamente ações preventivas e corretivas junto ao gerente do projeto e alta gerência.

O "relatório de avaliação de desempenho" evidencia esse grau de maturidade ao registrar que, na função produção, dimensão coordenação da produção, relatórios de atividades e acompanhamento são elaborados (Relatório Final de Pesquisa, 2020, p. 164). 
Somando-se a esta evidência o "relatório de auditoria" verificou que o monitoramento das atividades de atendimento ao contrato acordadas entre as partes sobre as tarefas a serem executadas durante as necessidades de pesquisa é realizado através dos relatórios de acompanhamento das atividades descritas no cronograma de execução (Relatório de Auditoria ISO 9001:2015, 2019, p. 15).

Reuniões de análise crítica são realizadas periodicamente com o intuito de identificar ações para tratamento de situações não conformes. O "relatório de avaliação de desempenho" cita execução de plano de ação oriundo da RAC como aprimoramento dos processos internos do EPP (Relatório Final de Pesquisa, 2020, p. 170).

Conforme dispõe o "relatório de avaliação de desempenho", originalmente a equipe do EPP estruturou-se como equipe de apoio de projetos da vice-presidência - tornando-se posteriormente um escritório de projetos, trazendo atividades, práticas e uma forma de organização de trabalho compatíveis à função de suporte aos pesquisadores e coordenadores de projetos (Relatório Final de Pesquisa, 2020, p. 17). Esta definição vem ao encontro da autoavaliação do EPP quando ele se vê no nível máximo, nível 3 da função prover mentoring para os gerentes de projetos, onde ele estrutura um processo para prover mentoring de forma proativa aos profissionais de gerenciamento de projetos do departamento conforme critérios pré-estabelecidos.

A matriz lógica dos processos de gerenciamento de projetos do EPP, documento anexo ao "relatório de avaliação de desempenho" nos mostra que a gestão estratégica de projetos, a qual engloba as atividades de monitoramento e controle, é uma atribuição do EPP (Relatório Final de Pesquisa, 2020, p. 48).

A transferência de conhecimento técnico pode ser evidenciada na ação de curto prazo (2018-2020) desenvolvimento de trilha de aprendizagem enquanto mecanismo estratégico do escritório (Rota Estratégica do EPP da Fiocruz, 2018, p. 1).

Ter um processo estruturado com o objetivo de captar e armazenar documentos de projetos do departamento analisando a qualidade da documentação e propiciando mecanismos de recuperação das informações aos usuários que de fato os utilizam leva o EPP ao nível 3, nível máximo da função gerenciar arquivos e acervos de documentação de projetos. Conforme depoimento abaixo da gestora do EPP, obrigatoriamente toda a tramitação de projetos é realizada pelo Sistema Eletrônico de Informações (SEI), onde toda documentação é recebida, analisada, arquivada e disponibilizada para consulta: "O SEl é um sistema do Governo Federal que somos obrigados a usar. Abrimos o processo virtualmente no SEl, não existe mais processo no papel. Não há projeto se não tiver o SEl" (Carneiro, 2020).
Gerenciar um ou mais programas ou projetos do departamento é uma função operacional autoavaliada também no nível 3, nível máximo desse quesito, onde o EPP oferece assistência aos gerentes de projetos/programas sempre que solicitado como metodologia e ferramenta específica, e em alguns casos assume ele próprio o gerenciamento de determinados projetos.

O "relatório de avaliação de desempenho" demonstra a utilização de metodologia específica pelo EPP onde relata que no critério institucionalização do EPP há uma metodologia adotada (Relatório Final de Pesquisa, 2020, p. 171).

O "relatório de auditoria" também dispõe que a metodologia dos processos está estabelecida nos POPs (procedimento operacional padrão) de cada processo (Relatório de Auditoria ISO 9001:2015, 2019, p. 10).

Como o EPP agrega profissionais muito capacitados em gerenciamento de projetos, estes, na maioria das vezes, gerenciam diretamente os projetos do seu portfólio, permitindo que profissionais capacitados nas disciplinas relacionadas às pesquisas desenvolvidas pela Fiocruz se dediquem exclusivamente à área técnica destes projetos.

Atuar proativamente no departamento possuindo um processo estabelecido de auditoria do gerenciamento de projetos com procedimentos de atuação e, além disso, utilizar os resultados da auditoria para fornecer feedback aos envolvidos é uma característica do EPP que o classifica no nível 3, nível máximo do modelo na questão conduzir auditorias de projetos. Conforme depoimento abaixo da gestora do EPP percebe-se que existe uma percepção do valor do trabalho de auditoria pelos auditados: "O papel do EPP é criar e aplicar o conhecimento na prática, sempre respeitando as normas da organização. Isso é feito por meio de auditorias, certificação da ISO que, além de cobrar os responsáveis, também servem para revisar e melhorar os métodos de trabalho a fim de otimizar processos. No mínimo anualmente são realizadas auditorias internas, quando um dos processos auditados sempre é a gestão administrativa (gerenciamento de projetos). Em duas auditorias internas realizadas em 2018 e 2019, o envolvimento e comprometimento evidenciado pela gestão e pelo setor da qualidade e o elevado envolvimento e empenho demonstrado pelos elementos participantes na auditoria foram destacados como principais pontos fortes" (Carneiro, 2020).

O "relatório de auditoria" mostra que a equipe auditora concluiu que o EPP cumpre os padrões e critérios de auditoria identificados e considera que o sistema de gestão continua a atingir os resultados pretendidos (Relatório de Auditoria ISO 9001:2015, 2019, p. 8).

Conduzir revisões pós-gerenciamento do projeto (lições aprendidas), mostrou ser um ponto de evolução, pois o EPP 
pretende sair do nível 2, onde facilita o processo de captação das lições, analisa, consolida e apresenta proposições de melhoria para projetos do departamento, para alcançar o nível 3, nível máximo desta questão para também estabelecer um processo integrado à metodologia para reaproveitamento das lições aprendidas por parte de outros gerentes em projetos atuais ou futuros do departamento. Uma preocupação com as lições aprendidas pode ser evidenciada em uma passagem no "relatório de avaliação de desempenho", onde é dito que para que seja possível que o alcance de metas seja satisfatório ao nível de produção do EPP, faz-se necessário um equilíbrio entre eficiência, efetividade e satisfação dos usuários, e que este equilíbrio é necessário para que a organização seja capaz de realizar alianças estratégicas institucionais e que propicie um ambiente organizacional que se transforme de acordo com as lições aprendidas dos desafios que se apresentam no âmbito da gestão dos projetos (Relatório Final de Pesquisa, 2020, p. 132).

Para alcançar o nível 3 acima citado, novamente pode-se recorrer, agora com as devidas adaptações, a algumas ações de médio prazo (2021-2024), tais como desenvolvimento da área de gestão em projetos e implantação da gestão de documentos no EPP (Rota Estratégica do EPP da Fiocruz, 2018, p. 2).

Finalizando a etapa da apresentação dos resultados, a Tabela 3 traz a apuração para a abordagem operacional.

\section{CONCLUSÃO}

Embora do ponto de vista temporal o EPP seja um escritório de projetos "novo", ele reúne todas as características de um escritório maduro no sentido de suprir as necessidades para o qual foi criado, gerenciando de forma eficaz os projetos vinculados à presidência da Fiocruz.
Em todas as abordagens propostas no modelo, o EPP mostrou encontrar-se no nível avançado, alcançando um percentual acima de $60 \%$ entre o atual e o desejado. A pequena diferença entre a pontuação alcançada no nível desejado para a pontuação máxima do modelo nos mostra o desejo de aderência quase que total para com as atribuições definidas pelo PMO Maturity Cube.

O EPP também mostrou ser um escritório versátil no sentido da amplitude da sua atuação, pois, apesar de constar no seu objetivo ser uma instância estratégica para a presidência da Fiocruz, verificou-se uma grande atuação nas esferas tática e operacional.

Pode-se inferir que no atual estágio o EPP é um escritório que atende os objetivos de sua criação, tendo em vista que a sua formatação e o modo como realiza o gerenciamento do seu portfólio de projetos atende às expectativas da Presidência.

\section{REFERÊNCIAS}

Aubry, M.; Hobbs, B.; Thuillier, D. (2008), “Organisational project management: an historical approach to the study of PMOs", International Journal of Project Management, Vol.26, No.1, disponível em: www.sciencedirect.com/science/article/ abs/pii/S0263786307001299 (acesso em 26 jul. 2020).

Carvalho, V.G., Barbalho, S.C.M. (2014), “Diagnóstico dos grupos de processo de gerenciamento de projetos com vista a implantação de PMO em uma fundação de apoio à pesquisa", artigo apresentado no XXI SIMPEP: Simpósio de Engenharia de Produção, Bauru, SP, 10-12 de nov. 2014.

Correia, C. de M. e S.; Moreira, C.M.; Muniz, R.M. (2018), “A importância da implantação do escritório de projetos: estudo de caso de uma organização de médio porte", Sistemas \&

Tabela 3. Resultados da Abordagem Operacional

\begin{tabular}{|c|c|c|c|}
\hline Questões de Abordagem Operacional & Nível Atual & $\begin{array}{l}\text { Nível Dese- } \\
\text { jado }\end{array}$ & $\begin{array}{c}\text { Nível Má- } \\
\text { ximo }\end{array}$ \\
\hline Como o PMO provê serviços especializados para os Gerentes de Projetos? & 1 & 2 & 2 \\
\hline Como o PMO informa o status dos projetos para a Alta Gerência? & 2 & 2 & 3 \\
\hline Como o PMO monitora e controla o desempenho de projetos e programas do departamento? & 3 & 3 & 3 \\
\hline Como o PMO provê mentoring para os Gerentes de Projetos? & 3 & 3 & 3 \\
\hline Como o PMO gerencia arquivos e acervos de documentação de projetos? & 3 & 3 & 3 \\
\hline Como o PMO gerencia um ou mais programas ou projetos do departamento? & 3 & 3 & 3 \\
\hline Como o PMO conduz auditorias de projetos? & 3 & 3 & 3 \\
\hline Como o PMO conduz revisões pós-gerenciamento do projeto (lições aprendidas)? & 2 & 3 & 3 \\
\hline Pontuação Total & 20 & 22 & 23 \\
\hline
\end{tabular}

Fonte: Os próprios autores

Resultado atual em relação ao desejado 90,91\% = Avançado

Resultado atual em relação ao máximo 86,96\% = Avançado

Resultado desejado em relação ao máximo 95,65\% = Avançado 
Gestão, Vol. 13, No. 2, disponível em: www.revistasg.uff.br/ sg/article/view/1207/855 (acesso em 24 jul. 2020).

da Silva, P.M.; de Carvalho, R.A.; Silva, S.V. (2018), "A importância da maturidade em escritórios de gestão de projetos: estudo de caso de um polo de inovação", GEPROS, Gestão da Produção, Operações e Sistemas, Vol. 13, No. 4, disponível em: https://revista.feb.unesp.br/index.php/gepros/article/ view/2039 (acesso em 01 jun. 2020).

Dinsmore, P., Cabanis-Brewin, J. (2009), AMA: Manual de gerenciamento de projetos, 1st ed., Brasport, Rio de Janeiro.

Fundação Oswaldo Cruz (n.d.), Site oficial da Fundação Oswaldo Cruz, disponível em: https://portal.fiocruz.br (acesso em 11 jul. 2020).

Kerzner, H. (2006), Gestão de projetos: as melhores práticas, 2nd ed., Bookman, São Paulo.

Khalema, L.S.; Van Waveren, C.C.; Chan, K.Y. (2015), "The relationship between project management office maturity and organisational project management maturity: an empirical study of the South African government infrastructure departments", South African Journal of Industrial Engineering, Vol. 26, No. 3, disponível em: www.scielo.org.za/scielo. php?script=sci_arttext\&pid=\$2224-78902015000300003\&la ng=pt (acesso em 02 ago. 2020).
Mansur, R. (2009), "Escritório avançado de projetos na prática: plano de negócio - a máquina de fazer dinheiro", 1st ed., Brasport, Rio de Janeiro.

Monteiro, A.; Santos, V.; Varajão, J. (2016), "Project management office models-a review", Procedía Computer Science, Vol. 100, disponível em: www.sciencedirect.com/science/article/pii/S1877050916324231 (acesso em 02 jun. 2020).

Pinto, A., Cota, M., Levin, G. (2010), "The PMO Maturity Cube, a project management office maturity model", artigo apresentado no PMI Research and Education Congress 2010, Washington D.C., USA, 11-14 de jul. 2010.

Pinto, G.O.; Mello, L.C.B. de B.; Spiegel, T. (2019), "Melhores práticas na implantação de um escritório de gerenciamento de projetos: uma revisão sistemática da literatura", Sistemas \& Gestão, Vol. 4, No. 4, disponível em: www.revistasg.uff.br/ $\mathrm{sg} /$ article/view/1580/html (acesso em 25 jul. 2020).

Project Management Institute (2017), PMBOK: Guide to the project management body of knowledge, 6th ed., PMI, PA, EUA.

Recebido: 31 out. 2020

Aprovado: 09 mar. 2021

DOI: 10.20985/1980-5160.2021.v16n1.1685

Como citar: Ramos J.A.P., Melo, L.M.M., Azevedo, E.B.A. (2021). Avaliação da maturidade de um escritório de gerenciamento de projetos da Fiocruz: um caso de sucesso. Revista S\&G 16, 1, 65-76. https://revistasg.emnuvens. com.br/sg/article/view/1685 